\title{
ENSAYO/ESSAY
}

\section{JOSÉ MARTÍ, ENTORNO HISTÓRICO}

Pedro Brufao García1: Especialista en Comunicación Social. España.

pedro.brufao@gmail.com

\section{RESUMEN}

El entorno histórico de José Martí se desenvuelve en un mundo donde se imponen dos potencias: Estados Unidos y Alemania. Reino Unido y Francia controlan el comercio y las materias primas, además del dinero. Las naciones y las alianzas entre ellas permiten el reparto de las colonias. Los mares son la gran vía de comunicación, complemento de la locomotora en el transporte de grandes volúmenes. Las máquinas de vapor, la electricidad y el motor se desarrollan a gran velocidad. La esclavitud está dando sus últimos coletazos. El Parlamentarismo está limitado porque el sufragio aún no es universal, pero el Liberalismo se va abriendo paso y el Estado democrático se plantea como garantía de los ideales comunes. Pero en esta carrera hacia el progreso España, preocupada por sus problemas internos, se está quedando retrasada. La población, empobrecida, sólo tiene una salida, la emigración, también la ideológica. El progreso político se suma al progreso industrial.

PALABRAS CLAVE: José Martí - Entorno histórico - Progreso político e industrial España - Prensa.

\footnotetext{
${ }^{1}$ Autor correspondiente:

Pedro Brufao García: Capitán de Infantería de Marina. Especialista en Comunicación Social. España. Correo: pedro.brufao@gmail.com
} 


\section{JOSE MARTI, HISTORIC ENVIRONMENT}

\section{ABSTRACT}

The historic surroundings of Jose Marti takes place in a world where two powers are imposed: United States and Germany. United Kingdom and France control trade and commodities, besides money. The nations and alliances between them allow the division of colonies. The seas are the great means of communication, in addition to the locomotive transporting large volumes. The steam, electricity and motor develop at high speed. Slavery is on its last legs. The Parliamentary system is limited because it is not yet universal suffrage, but is making inroads Liberalism and the democratic state arises as a guarantee of common ideals. But in this race towards progress Spain, preoccupied with its internal problems, it is falling behind. The population, impoverished, has only one output, emigration, also ideological. Political progress adds to industrial progress.

KEYWORDS: Jose Marti - Setting historical - Political and industrial progress - Spain Press.

El entorno histórico de José Martí se desenvuelve en un planeta totalmente explorado, conocido y cartografiado que soporta una población de mil millones de personas de los cuales una cuarta parte son americanos y europeos.

En este mundo se imponen dos potencias, los Estados Unidos, que abraza a la isla de Cuba, y Alemania. Estas dos naciones se están destacando por su industria, mientras que el Reino Unido y Francia son realmente los banqueros de la Sociedad, que solo habla en libras o francos cuando se refiere a las grandes transacciones mercantiles. En este marco Rusia y Japón aún no son representativos. Londres controla el comercio y los pagos de las materias primas, mientras Paris acoge los ahorros individuales de los cinco continentes porque ofrece los mejores dividendos y las mayores garantías.

El mundo de las naciones y de las alianzas está en ebullición repartiéndose las colonias de África, Asia y Oceanía.

Los mapas son un producto codiciado, donde las fronteras se mueven con facilidad por los acuerdos y las ocupaciones, en ellos se buscan nombres desconocidos que la prensa cita con alarde de titulares y sensacionalistas imágenes.

Los mares, antes obstáculos, son la gran vía de comunicación que una vez abierta no se cierra jamás porque no necesita ningún mantenimiento, sólo unos puertos de apoyo que aseguren el carboneo y el agua dulce.

Las grandes llanuras también han sido conquistadas por las locomotoras que resisten miles de kilómetros, el ferrocarril complementa al transporte de los grandes 
volúmenes que se mueven por el mar.

Por todo esto, gracias a los grandes inventos y a un esfuerzo de capitales que arriesgan y los apoyan, se están desarrollando a gran velocidad las máquinas de vapor, la electricidad y el motor.

La distancia ha sido vencida y las comunicaciones, entre los hombres y los productos se mueven con una facilidad mejorada en factores que son múltiplos de 10 y hasta de veinte enteros. Era el principio del fin del espacio como obstáculo de dificultad en las relaciones.

Es una época maravillosa y bárbara a la vez en la que se pueden escuchar las mejores composiciones musicales y los últimos latigazos de la esclavitud., los motores de este periodo son las filosofías y el dinero, dando las religiones un definitivo paso atrás.

Todos los adelantos anteriores han influido profundamente en las estructuras sociales y las corrientes filosóficas de los pensadores se decantan en dos grupos antagonistas, los que son partidarios del autoritarismo y los demócratas.

El parlamentarismo está limitado porque el sufragio universal aún está sujeto y limitado a los hombres que reúnen unas condiciones determinadas de posición social y de posesión de bienes. Poco a poco el liberalismo se va abriendo paso y el Estado democrático se plantea como garantía de los ideales comunes para corregir los excesos que pudieran producirse.

En esta carrera hacia el progreso España se está quedando francamente retrasada y estancada en un liberalismo que no deja paso a la democracia, su estructura sigue siendo esencialmente rural y las energías políticas, económicas y militares se malgastan en resolver problemas dinásticos y de gobierno totalmente domésticos, mientras las demás naciones de su rango inicial se van configurando como potencias coloniales, industriales, financieras, mercantiles y militares.

Preocupados los españoles por sus problemas internos, no llegaron a ver clara la importancia que tenía el fomento de la fuerza naval capaz de apoyar la política internacional del gobierno y así se abandonó el esfuerzo necesario en buques, hombres y dinero.

Es una época abundante en paradojas, así vemos como la poderosa y rica Europa se encuentra con una superpoblación en gran proporción empobrecida, que sólo tiene una salida, la emigración, mayoritaria hacia el continente americano. Mientras ríos de pobres emigrantes ingleses, españoles, portugueses, franceses, rusos y un largo etcétera cruzan el Atlántico en busca de trabajo, Europa marca el rumbo del mundo, siendo sus industrias, bancos y universidades los de mejor calidad.

Todo esto se debe a que el propio progreso ha hecho disminuir la mortalidad, ya no hay grandes epidemias aunque la tuberculosis y la viruela siguen siendo motivo de gran preocupación. 
En España el Índice de mortalidad ha disminuido en un 19,3 por ciento, un 18 por ciento en Francia, un 30 por ciento en Italia, un 28,6 en Gran Bretaña y un 30,7 por cien en Alemania.

La superpoblación de parados se debe a la modernización agrícola y de la industria, los que logran crear puntos de trabajo al mismo ritmo de sus necesidades demográficas, consiguen frenar la emigración como le sucedió a los alemanes que dejaron de emigrar al filo del año 1896.

A estas causas hay que unir la emigración ideológica que ha existido en flujo constante a través de las épocas. Los irlandeses enfrentados por ser católicos o protestantes, Francia con sus problemas de la Comuna, los eslovacos empujados por la magiarización hacen de Cleveland Estados Unidos su ciudad más populosa. Los judíos están huyendo de la tormenta que se les avecina, llegando a cuajar en la Segunda Internacional (1889), todos estos movimientos consecuencia del fracaso de la comuna de 1871, tienen unos brotes desesperados de anarquismo que culminan en importantes atentados mortales a hombres de Estado.

La relativamente lejana Revolución francesa sigue siendo un modelo nacional de vida en común a imitar en las ex colonias americanas o en proceso de emancipación. No hay intelectual que se precie que no haya leído las obras de Montesquieu, Rousseau, Voltaire y Kant.

En la época de José Martí ha triunfado en el mundo el liberalismo, al menos conceptualmente y la democracia en el sistema político de gobierno aceptado por la intelectualidad.

Al progreso político se ha unido un imparable progreso industrial basado en los grandes inventos. Son de la misma época que José Martí, el químico sueco Alfredo Nobel (1833-1896) que inventó la dinamita y creó el premio universal más prestigioso en varios campos del saber. El español Isaac Peral, inventor del submarino como arma de guerra, personaje incomprendido y victima de envidias. El alemán Karl Benz fabricó el coche movido por un motor de combustión interna, en realidad lo que patentó fue un triciclo motorizado (1886). El estadounidense Flurnan Edison junto con el inglés Joseph Swan inventaron la bombilla eléctrica de incandescencia. Graham Bell de origen escocés inventó el teléfono que tantísimo influyó después en la confección de los periódicos. Un grupo de ingenieros franceses (1876) construyeron barcos mercantes que podían llevar carga refrigerada, esto fue decisivo en el transporte de la carne que hasta este momento tenía que hacerlo con el ganado en vivo.

La aglomeración en las ciudades trajo el invento del rascacielos que nacieron en Chicago hacia 1884. Estas mismas aglomeraciones llevaron a la construcción de los trenes subterráneos que empezaron a circular en la ciudad de Londres. El invento del automóvil que apareció de la mano del motor de gasolina trajo con la investigación específica otros adelantos como la del neumático patentado por Dumplop en Escocia. Otro invento de gran impacto social fue la fotografía que comenzó su gran expansión 
hacia 1851 en placas de cristal y su posibilidad de traslado al papel, es decir a los periódicos , y también aparece en escena el arma principal del periodista, la máquina de escribir que empezó a producir en serie por la casa Remington en 1873. La radio comienza sus balbuceos con el final de la vida de José Martí y es el italiano Guillermo Marconi el primero que consigue una emisión por este sistema en 1894.

Por esta misma época comienza el cine, siendo sus precursores los financieros Lumiére (1895). Otro gran invento fue la creación las agencias de noticias, siendo primera la agencia Reuter nacida en Alemania en 1.958. La interconexión mundial exigía atrapar el tiempo de forma universal y por convenio se decide que la hora patrón dada para Gran Bretaña por el Observatorio Real de Greenwich sea 1884 la hora oficial para el mundo entero.

La salud y todo lo que afecta al hombre es motivo de gran preocupación y la ciencia libre de los corsés que la limitaban se lanzan a la investigación y en 1856 el francés Pasteur descubre las vacunas en 1856 y Darwin en 1859 explica las teorías de la evolución. En contraposición los avances para mejorar y preservar la vida, el hombre aprende a matar e inventa el fusil de cerrojo (Maner) y las ametralladoras que dispara 600 balas por minuto en un radio de un kilómetro (1890). Se puso de moda la sencilla bicicleta que patentó su primer modelo en 1879. Todos estos adelantos llevaban a un gran consumo de energía que entonces sólo procedía del carbón y del petróleo, para ahorrar esta energía y el tiempo en los transportes se construyen los grandes canales de navegación poniéndose en servicio el de Suez en 1869 y el de Kiel en 1895. Esta es la panorámica general del progreso en el área de los inventos y ahora haremos un recorrido por el mundo de las artes y las letras.

Prescindiendo de rangos y de cronologías quiero comenzar haciendo referencia al gran poeta nicaragüense Rubén Darío (1867-1916) gran amigo del que también fue un magnifico poeta José Martí. La gran estrella de la literatura en esta zona histórica es León Tolstoi gran novelista nacido en el corazón de Rusia. En música el mundo se deleita con las obras de Beethoven, Schubert y Chopin. El pensamiento filosófico está presidido por Marx, Malthus y Nietzsche.

La política de las grandes potencias que orientan los rumbos del mundo está patrocinada en Inglaterra por Benjamín Disraelí, de origen judío, que consiguió la gran expansión del imperio británico que llegó a la India, sin descuidar grandes reformas sociales, aumentando el sufragio en grandes proporciones; es uno de los pilares doctrinales de la democracia conservadora.

En Estados Unidos brilla con lucidez Abraham Lincoln director y vencedor de la guerra de Secesión, consiguió las bases para llevar a su nación al nivel de gran potencia. El otro pilar fuerte de Europa es el Canciller de Prusia, Otto Von Bismark, de carácter autoritario, lo que no fue obstáculo para impulsar una legislación de seguridad social muy avanzada. En España en la época de José Martí fue de cambios continuos con una mentalidad política casi constante lo que imposibilitaba desarrollar cualquier acción de gobierno ni siguiera a corto plazo. Hemos tenido desde 1833 una monarquía, una república (1873) y nuevamente la monarquía con dos regencias y 
desde 1812 a 1876 siete constituciones.

Desde 1874 en que se celebran las segundas elecciones de la Restauración el asunto Cuba es la cuestión más candente de los gobiernos, problema que habría tenido sus orígenes en septiembre de 1868 cuando el hacendado cubano Carlos Manuel de Céspedes dio el grito de "Cuba Libre" en Yara- A la vez en la Península se están librando las sangrientas guerras carlistas, acabadas felizmente en 1876 y en ese mismo año mandó a Cuba al General Arsenio Martínez Campos, con las fogueadas tropas que hablan intervenido en el norte de España. Con prudencia y energía consiguió la Paz del Zanjón y la concesión de las mismas condiciones autonómicas que Puerto Rico.

En España se suceden los gobiernos conservadores y liberales, Estados Unidos apoya casi abiertamente a los insurrectos y el ejército español pierde la vida de cien mil soldados en tres años, la mayoría víctimas de las pésimas condiciones sanitarias que se les podían ofrecer. El Rey Alfonso XII comprometió la Corona en los cambios y trasiegos políticos, en vez de mantener una exquisita independencia. A la vez los desordenes y asesinatos se suceden con cierta impunidad siendo notables las acciones anarquistas de la Mano Negra y también los militantes de la Asociación Republicana Militar (ARM) con fuerte inspiración masónica, inician una serie de pronunciamientos.

El Rey realizó un viaje a los imperios centrales en busca de apoyos y solo recibió frialdad lo que provocó, por reacción, una mayor adhesión del pueblo español. En 1888 Moret consigue la vinculación de España a la Triple Alianza (Alemania, Austria e Italia). Eran los tiempos en que las relaciones multinacionales y los equilibrios para la paz sólo se sustentaban en la amenaza. La mala salud del Rey era un hecho tangible y habla movimientos para reponer en el trono a dofta Isabel II depuesta en 1868. El Almirante Antequera presentó la dimisión cuando se anularon los planes de construcciones navales tan necesarios en los inicios de un conflicto totalmente ultramarino. Alemania quería las islas Carolinas que aunque dependientes del Capitán General de Filipinas, están prácticamente abandonadas. Alfonso XII fallece en el Palacio del Pardo el 25 de noviembre de 1885 y la única salida legal fue la regencia de Ma Cristina, llevando todo el peso de momento tan delicado, el gran estadista Antonio Cánovas del Castillo. Por el Pacto de El Pardo se sucederán Cánovas y Sagasta. Y en este estado de cosas sucede el tópico incidente del Maine en la rada de la Habana. El conflicto con los Estados Unidos y la pérdida de Cuba, Puerto Rico y Filipinas, enclaves necesarios para dar el espaldarazo al nacimiento de la gran potencia Norteamericana.

La prensa en España desde 1868 a 1898 pasa como muy poco por tres etapas, la descomposición de la prensa Isabelina de 1868 al 74, la consolidación de la prensa burguesa 1875 al 98 y la crisis de prestigio subsiguiente a la calda de las colonias. En el primer periodo aparecieron quinientos noventa y seis periódicos de todas clases y especialidades, todos ellos de cortísimas tiradas- La prensa de partido que consigue sobrevivir representa al moderantismo (La Época), el progresismo (La Iberia) y el carlista (La Esperanza).

Derrocada Isabel II aparecen nuevos periódicos para imponer su solución política y se 
lanzan los carlistas con "El pensamiento Español, La Fidelidad, La República, El Legitimista Español y otros como La Cruzada, Altar y Trono, El Padre Cobos, El Gato , El Fraile, etc.

Como republicano y diario democrático "La Discusión" y como internacionalistas "Solidaridad", "La Federación y la Emancipación".

Pero la prensa de masas aún no se abre camino franco a pasar de los vientos favorables de los conflictos en Cuba y Filipinas. Los primeros periódicos que disfrutaron de edificio propio fueron La Iberia, La Correspondencia de España, La Época, El Imparcial, El Liberal y El Heraldo de Madrid.

El periódico con la plantilla más numerosa era La correspondencia de España, que contaba con un director, un redactor jefe, secretario de dirección, cuatro redactores generales y seis redactores políticos.

En 1879 aparece una aperturista ley de prensa porque no era suficiente la Constitución de 1876, en la que se declaraba la "libertad de emisión de pensamiento" para que la oposición pudiera ejercer su acción, y sencillamente no se concedía licencia a los periódicos que se estimaban peligrosos.

Al fin en 1898 se levantan las barreras para que el "cuarto poder" pueda tener más posibilidades, la prensa nacional se especializa y la provincial que no se puede permitir esos lujos profundiza en los temas de intereses locales y regionales. Por tener un ejemplo en 1899 existían más de 360 títulos de publicaciones dedicadas al mundo de los totos, y en las publicaciones gráficas destacan por su gran calidad La Ilustración Española y Americana (fundada en 1869); Blanco y Negro (1891) y el Nuevo Mundo (1894), en la prensa política hay que señalar $L a E ́$ Eoca, de los conservadores y El Imparcia/ de los liberales y monárquico.

Como resumen de la prensa en España en la época de José Martí podemos decir que es diversa, numerosa y controlada por partidos o grupos políticos y el nacimiento de una "prensa ilustrada" que tiene una progresiva buena acogida por la sociedad en general.

En el resto del mundo la prensa se presenta así: En Alemania proliferan las "revistas", como en Francia, Inglaterra e Italia, algunos de cuyos titulares han llegado hasta nuestros días; la mayoría son revistas especializadas en economía, medicina, industria, geografía, naturaleza, agrícolas y militares.

En Europa destacan por su calidad los alemanes, austríacos, rusos, ingleses, franceses e italianos.

En América son muy importantes los de Argentina, Bolivia, Brasil, Colombia, Costa Rica, Ecuador, Guatemala, Méjico, Nicaragua, Paraguay, Perú y Caracas. Sus nombres más destacados son, La Nación, El Heraldo, El Imparcial y El Sol.

El periodismo norteamericano merece renglón aparte por un desarrollo y por la 
importancia que tuvo en el desarrollo de los acontecimientos en la zona caribeña, donde la información pública conformó la opinión generalizada. La empresa periodística es aquí una gran inversión que dota a las redacciones de grandiosos edificios, con numerosas plantillas de periodistas y corresponsales, con medios de reproducción y distribución propios, gozando de los últimos adelantos de las comunicaciones por teléfono, telégrafo y cable submarino.

En cuanto al periodismo en la propia Cuba, Polavieja le dedica un amplio informe con el que pide al Ministro de Ultramar que se modifique en la Gran Antilla la ley de Imprenta para evitar los males que producía, y se ocupa con interés de todo lo que publican: El Machete, La Cebolla, la Tribuna, La Lucha y la Fraternidad. Hay bastantes sentencias que la Audiencia de la Habana consideran constitutivas de delito por parte de periodistas, que vistas en Madrid en recurso de casación son anuladas.

Todo esto al amparo del artículo 13 de la Constitución que concedía a todo español el derecho de emitir libremente sus ideas y opiniones, valiéndose de la imprenta o de otro procedimiento semejante. También fue de gran motivo de preocupación para el gobierno de la Isla la proliferación de pasquines que se pegaban en la puerta de las iglesias.

Al otro lado del mundo en la isla de LUZON (Filipinas), el Gobernador Blanco también cuenta a Madrid los quebraderos de cabeza que le produce la prensa y otras publicaciones en las que se atacaba su acción gubernativa.

Mientras tanto en Madrid el presidente del Consejo de Ministros D. Antonio Cánovas del Castillo decía: "Consumiremos para defenderlas (Las Antillas) la última gota de sangre y la última peseta". Cánovas estaba resuelto con la mediación de las potencias llegar a un arreglo honroso pero antes murió asesinado por el anarquista italiano Miguel Angiolillo (8- Agosto-1897), con la muerte de Cánovas, la Monarquía perdía su más valioso y leal colaborador y así lo reflejó la prensa de todo el mundo. Tenía previsto retirarse a la vida privada una vez que hubiera resuelto el problema de Cuba.

José Martí no consiguió su gran y honesto ideal y Cuba desgajada de España comenzó a regirse por su Constitución de 21 de Febrero de 1901, adicionada en 12 de junio del mismo año, y en virtud del tratado de 22 de Agosto de 1903 sujeta al Gobernador de los Estados Unidos, Charles Magoon. Las relaciones diplomáticas con España se restablecieron pronto y en 1908, Ramón Gaytan de Ayala, era ministro plenipotenciario y enviado extraordinario en la Habana con un amplio despliegue consular.

De aquella agitada época nos han quedado vocablos en España que recuerdan nuestra pasada vida en común, aunque a veces no lo sepamos. Las enaguas o naguas eran las hojas de plátano ceñidas a la cintura que cuanto más largas más del grupo de los "casiques".

En Andalucía se denomina al barucho como un "bujío" que en Cuba era una choza, y quién no ha descansado en una hamaca ("jamaca"). Todos sabemos que un cayuco es 
una canoa pequeña y que un "guateque" es un baile bullicioso.

Los hombres que abanderan a sus pueblos son siempre unos grandes poetas porque aman profundamente a su tierra y así en Filipinas, José Protasio Rizal y Alonso, con ocho años ya escribía poemas, educado en los Jesuitas, también viene a España para completar su formación y obtiene los títulos de médico y licenciado en filosofía en el año 1884 y en 1885 el doctorado, también fue periodista en La solidaridad y con 23 años pronunciaba su credo político hablando en Manila el 30 de Diciembre de 1896.

Y para finalizar quiero incluir como cierre de esta sucinta panorámica el Discurso leído por S.M. la Reina en el Congreso en la solemne apertura de las Cortes del 20 de abril de 1898, cuando faltaban doscientos cuarenta días para la ratificación del Tratado de Paris.

\section{Discurso leído por S. M. la Reina en el Congreso, en la solemne apertura de las Cortes del 20 de abril de 1898}

\section{Señores Senadores y Diputados:}

Las graves preocupaciones que embargaban mi ánimo y el de la Nación, la última vez que os dirigí la palabra, han aumentado su pesadumbre y avivado la inquietad pública con el presentimiento de nuevas y mayores complicaciones.

Motívalas el giro que a los asuntos de Cuba da la actitud de una parte del pueblo de los Estados Unidos, que, al ver pronta y cercana la Constitución que aquella personalidad, solemnemente ofrecida a las Antillas en anterior mensaje, presienten que la libre manifestación de la voluntad del pueblo cubano, representada por sus Cámaras, va a destruir para siempre los planes que contra la soberanía de España vienen fraguando los que, con recurso y esperanzas enviados de las vecinas costas, han logrado mantener el fuego de la insurrección de aquella desgraciada Isla.

Porque si a esa ciega corriente se viera en mal hora el Gobierno "de los Estados Unidos, las amenazas y las injurias a que hasta ahora hemos podido permanecer indiferentes por no ser expresión genuina de la nación americana, se tornaría en provocación intolerable, en defensa de la dignidad nacional, obligarían a mi Gobierno a romper nuestras relaciones con el de Washington.

En esta crisis suprema la voz sagrada de quien representa en la tierra la justicia divina ha hecho oír consejo de paz y de prudencia que ninguna dificultad ha tenido en seguir mi Gobierno, sintiéndose fuerte por su derecho, intranquilo por el cumplimiento estricto de sus deberes internacionales.

Y si al Santo Padre debe España gratitud profunda por su intervención en favor de la paz en estos críticos momentos, obligada queda también a las grandes potencias de Europa, que con su conducta amistosa y su desinteresado consejo han fortalecido nuestra convicción de que la causa de España merece universales simpatías y su actitud aprobación unánime. 
Posible es, sin embargo, que el atentado se consume, y que ni la santidad de nuestro derecho, ni la moderación de nuestra conducta, ni la expresa voluntad del pueblo cubano, libremente manifestada, sirvan para contener las pasiones y los odios desencadenados contra la Patria española. Y por si llega ese supremo momento, en que la razón y la justicia tengan por único amparo el valor de los españoles y la tradicional energía de nuestro pueblo, que ha acelerado la reunión de las Cortes, cuya decisión suprema sancionará sin duda la inquebrantable resolución que anima a mi Gobierno de defender nuestros derechos, cualquiera que sea el sacrificio que para lograrlo se nos exija. Al identificarme así con la nación no sólo cumplo los deberes que juré al aceptar la Regencia; busco también fortalecer mi corazón de madre, confiando en que el pueblo español, agrupándose en derredor del Trono de mi hijo, le sostendrá con su fuerza incontrastable, mientras llega el momento en que a él sea dado defender personalmente el honor de su nación y la integridad del territorio que nos legaron nuestros gloriosos antepasados.

A los graves asuntos que de esta suerte solicitan vuestra atención hacia los mares de Occidente viene a unirse el estado de nuestras posesiones en el lejano Oriente. Las Islas Filipinas, cuya lealtad ha puesto a prueba una grave insurrección, felizmente dominada, sienten todavía las consecuencias de aquella agitación profunda. Para calmarla y para prevenir en lo futuro el descontento, remediando las causas del anterior malestar, mi Gobierno os someterá importantes resoluciones.

\section{Señores Diputados y Senadores:}

Por obscuro y sombrío que el porvenir se nos presente no han de ser superiores las dificultades que nos rodean a las energías del país para vencerlas. Con un ejército de mar y tierra cuyas gloriosas tradiciones enardecen su valor ingente; con una nación unida y compacta ante la agresión extranjera, y con aquella fe en Dios que guió siempre a nuestros mayores en las grandes crisis de la Historia, atravesaremos también, sin mengua de nuestra honra, la que hoy se intenta colocarnos sin razón y sin justicia.

\section{Pedro Brufao García}

Capitán de Infantería de Marina de la Real Armada Española. Especialista en la Guerra de Cuba y en Comunicación Social. Ha escrito varios artículos sobre este tema. 